\title{
European Federation of Societies for Ultrasound in Medicine and Biology
}

\section{EFSUMB Guidelines Update}

\section{Dermatological Ultrasound Guidelines}

Dermatological Ultrasound is progressively being implemented in both radiology and dermatology services in Europe. The possibility of sonographic diagnosis of cutaneous, hair and nail diseases with high frequency probes and the rising number of aesthetic procedures complications have evidenced the need for this application in the contemporary ultrasound arena.

As a result the first Dermatologic Ultrasound Course recently hosted by EFSUMB that took place in Madrid ULC $1^{\text {st }}$ and $2^{\text {nd }}$ June 2018 was a success with more than 80 participants both radiologists and dermatologists who were interested in acquiring the principles and main applications of this technique in a clinical setting.

As dermatological ultrasound is here to stay, guidelines of proper technical and clinical application have become necessary. In that sense. ESUMB is fostering the ela- boration of consensus guidelines of Dermatological Ultrasound with the cooperation of expert radiologists, dermatologists and sonographers working in the dermatological ultrasound knowledge field.

\section{Point of Care Ultrasound Guidelines}

EFSUMB has established a steering committee and authors to begin the task of PoCUS guidelines. Hopefully the final document will provide the best evidence for training and practice in point-of-care ultrasound. Not all parts of Europe are at the same level with regards to established PoCUS practice but this document will go a long way to standardising things and providing support.

\section{Elastograhy non-liver Ultrasound Guidelines}

These guidelines are almost ready for submission for publication. Consult the
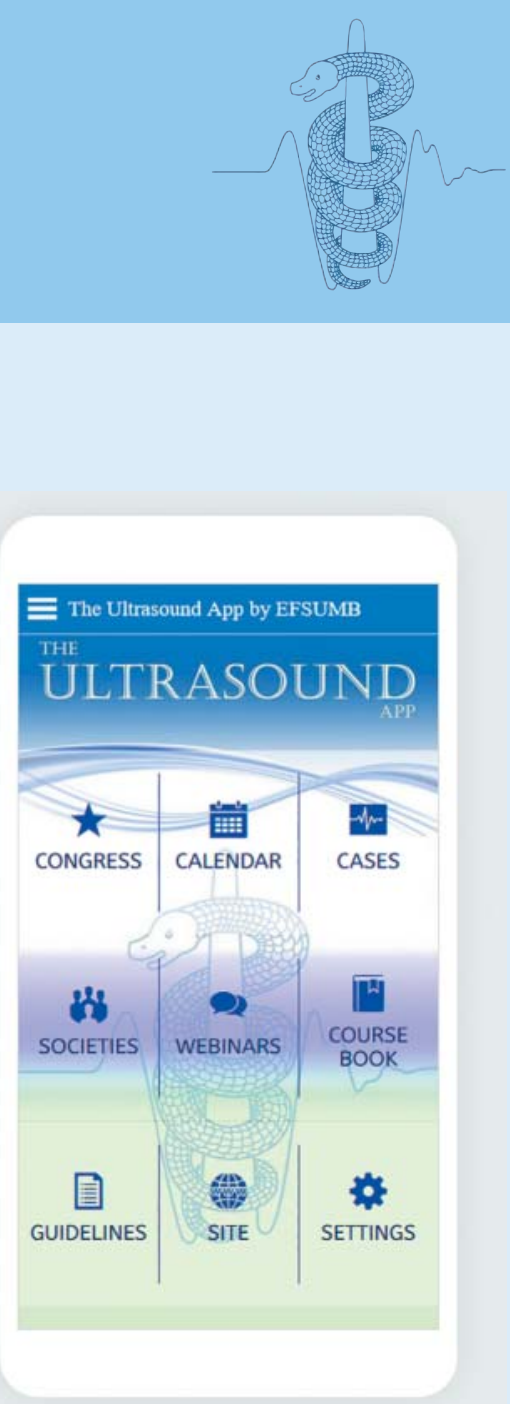

EFSUMB App to download these as soon as published. 